\title{
Eisenstein no Brasil: uma breve introdução*
}

\author{
Fabiola Bastos Notari**
}

Resumo: Por que ver, ler e falar de Serguei M. Eisenstein hoje? Qual a importância deste cineasta para o público brasileiro? Neste artigo apresento de maneira breve e sucinta as discussões desenvolvidas na tese Eisenstein no Brasil. Trata-se de uma pesquisa inédita sobre a influência que a teoria e os filmes de Eisenstein tiveram sobre alguns acontecimentos histórico-culturais no Brasil, ou mais especificamente sobre a atuação de determinados intelectuais e instituições que foram apoiadores, divulgadores e defensores da linguagem cinematográfica como expressão artística.

\begin{abstract}
Why watch, read, and talk about Sergei M. Eisenstein today? How important is this filmmaker to the Brazilian public? In this article I present briefly and succinctly the discussions developed in the thesis Eisenstein in Brazil. The thesis presents an unprecedented research on the influence that Eisenstein's theory and films had on some historical-cultural events in Brazil, or more specifically on the performance of certain intellectuals and institutions that were supporters, disseminators and defenders of cinematographic language as artistic expression.
\end{abstract}

Palavras-chave: Serguei M. Eisenstein; crítica e interpretação; história; linguagem cinematográfica; recepção crítica.

Keywords: Sergei M. Eisenstein; Criticism and interpretation; History; Cinematography; Critical reception. 
"O leitor tem de aceitar o inconformismo de Eisenstein e por isso, embora todo 0 verdadeiro estudioso do cinema deva ler Eisenstein, o prazer da leitura limitar-se-á às suas aventuras mentais. Apesar de excêntrico, era um pensador erudito, um apaixonado por filosofia, arte, política e filologia e o fruto destes estudos está bem aparente e visível em seus ensaios."

(Roger Manvell)

\section{Breve introdução}

* Artigo submetido em 28 de maio e aprovado em 04 de junho de 2018. Este artigo é parte da tese de doutorado Eisenstein no Brasil, 2018, USP, realizada com auxílio da FAPESP.

**Doutora pelo Programa de Literatura e Cultura Russa do Departamento de Letras Orientais da Faculdade de Filosofia, Letras e Ciências Humanas da Universidade de São Paulo, mestre em Poéticas Visuais pela Faculdade Santa Marcelina (FASM/ASM) e bacharel em Artes Visuais pelo Centro Universitário Belas Artes de São Paulo, onde leciona desde 2012. Coordenadora do Grupo de Estudos "Livros de artista, livros-objetos: entre vestígios e apagamentos na Casa Contemporânea", desde 2014, e é programadora visual da produtora cultural Ars et Vita. www.fabiolanotari. com. E-mail: bionotari@gmail.com
São raras as pesquisas cujos projetos iniciais não sofrem transformações, uma vez que a própria dinâmica do seu desenvolvimento apresenta fatos e/ou situações que não poderiam deixar de ser inseridos ou de assumir posições que lhes são inerentes. Assim, neste trabalho, percebe-se que no tema proposto, Eisenstein no Brasil, não seria possível dissociar do antigo e atual cenário brasileiro a relação política, social, ideológica e cultural da vida e obra deste grande cineasta, teórico, professor e artista que foi Serguei Mikháilovitch Eisenstein.

Eisenstein no Brasil não é um trabalho sobre a vida e obra do grande cineasta russo-soviético; o que apresento neste artigo são questionamentos que permitem uma reflexão a respeito da influência que a teoria e a filmografia de Eisenstein tiveram sobre acontecimentos histórico-culturais no Brasil ou, mais especificamente, sobre a atuação de determinados intelectuais e instituições que apoiaram, divulgaram e defenderam a linguagem cinematográfica como expressão artística.

Durante as pesquisas de campo e teórica para este trabalho, configurou-se um cenário abrangente, em que Eisenstein constituía o ponto de contato. Nessa rede de conexões, decidiu-se esboçar um diagrama de conjuntos sobre alguns universos tangenciados pela sua produção artístico-teórica seus escritos e filmes.

No diagrama que traça uma estrutura conceitual e gráfica da tese, são observados o desenvolvimento da crítica cinemato- 
gráfica, a produção do cinema nacional brasileiro, a criação e expansão do movimento cineclubista associado à difusão das cinematecas, a sistematização e o estudo da teoria do cinema, as traduções de livros e artigos sobre cinema, a criação de cursos superiores de cinema, os movimentos sociopolíticos relacionados à valorização da cultura e ideologia soviética e, no movimento contrário, a censura.

Certas ideias são concretizadas em momentos pouco adequados. Apesar disso, substituem e superam as contradições da própria realidade e de si mesmas, na dinâmica de um constante e afirmativo vir a ser, cada vez mais aprimorado. Tais situações associadas a Eisenstein, ora políticas ora artísticas, pelas dificuldades enfrentadas e pela grandeza de suas experiências, justificam por si só o mister da elaboração deste trabalho.

A admiração que Eisenstein despertou no público brasileiro em diversas épocas infelizmente não foi registrada com tanto cuidado quanto as manifestações de exaltação e crítica de teóricos da linguagem cinematográfica e cineastas, entre eles Paulo Emílio Sales Gomes, um de seus maiores entusiastas e difusores, e Glauber Rocha, que nunca escondeu seu fascínio pelo cineasta russo-soviético.

A tese Eisenstein no Brasil aproxima e sistematiza os mais diversos materiais pesquisados: livros, teses, jornais, revistas, entrevistas e artigos, a partir de um recorte, até então o mais completo, da influência eisensteiniana em território nacional.

Ela se divide em três partes fundamentais, que se configuram a partir do diagrama de conjuntos a serem seguidos como guia de leitura. É importante indicar o modus operandi da tese, o que possibilita uma experiência teórico-visual a partir da formatação do texto no espaço da página em paralelo ao desenvolvimento do mesmo. A proposta é uma leitura contemporânea de Eisenstein a partir de componentes da montagem cinematográfica proposta por ele para a análise de um passado histórico e cultural, reunido por meio de pesquisa de campo e teórica, que reverbera até os dias atuais. 
Trata-se de uma tese sobre a influência de Eisenstein no Brasil, elaborada em um programa de literatura e cultura russa, escrita por uma artista. O resultado não poderia ser diferente. $O$ trabalho foi iniciado há bastante tempo, mas a realização de uma pesquisa mais sistematizada data dos últimos quatro anos.

É importante ressaltar que as transliterações do russo para o português têm como base a tabela apresentada na revista Caderno de Literatura e Cultura Russa. ${ }^{1}$ Optou-se utilizar a acentuação mais próxima possível da fonética russa, com o intuito de auxiliar o público brasileiro na pronúncia. Há muitas controvérsias quando o assunto é transliteração. Alguns nomes possuem variação gráfica, pois em alguns momentos mantém-se a grafia original da publicação citada, como é o caso de Alexandre/Alesándr/Aleksander/Aleksandr Nevsky/ Nevski/Niévski e Couraçado/Encouraçado Potemkin/Potiómkin. Com relação aos nomes de artistas, teóricos e cineastas já conhecidos do público brasileiro, a opção foi transliterar a partir da pronúncia russa, dessa maneira, o nome Sergei foi substituído por Serguei.

O diretor, como imagina Eisenstein, é simultaneamente um arquiteto, um poeta, um pintor, um compositor, mas sobretudo um artista cinematográfico no mais honrado e mais alto senso da palavra. Um artista que pensa sinteticamente, um artista inovador que abre novos caminhos, o infatigável descobridor e criador de novas formas capazes de mexer com a mente e o coração e ganhar a simpatia do espectador. ${ }^{2}$

Devo preveni-los imediatamente: estas anotações são completamente imorais. Ao mesmo tempo devo decepcionar aqueles que esperam vê-las recheadas de episódios imorais, detalhes sugestivos ou descrições obscenas. Não se trata disso de modo algum. Diante de vocês não terão - como direi - um Casanova vermelho e muito menos um relato dos episódios amorosos de um diretor de cinema russo. ${ }^{3}$

\footnotetext{
1 Publicação do Curso de Língua e Literatura Russa do DLO/FFLCH da Universidade de São Paulo. 2004.

2 NIZHNY, 1964, p. 14.

${ }^{3}$ EISENSTEIN, 1987, p.33.
} 


\section{Diagrama de conjunto, o modus operandi da tese}

A palavra diagrama pode significar desenho, registro, esboço, enfim, uma representação por meio de linhas. ${ }^{4}$ Compostas por desenhos e palavras numa relação dinâmica, essas estruturas plásticas indicam o caminho a ser percorrido para a construção do pensamento, auxiliando no processo de elaboração da tese. O diagrama em Eisenstein no Brasil é utilizado como ferramenta metodológica e demonstra ao leitor a trama de articulações entre pesquisa e discurso.

Representados por curvas fechadas simples, traçadas sobre um plano, os conjuntos permitem a representação das relações de pertencimento entre os conjuntos e seus elementos. Do mesmo modo, os espaços internos comuns a dois ou mais conjuntos representam a sua interseção, ao passo que a totalidade dos espaços pertencentes a um ou outro conjunto representa indistintamente sua união (figura 1).

Esses conjuntos constituem, respectivamente, as partes da tese, as quais apresentam as influências de Eisenstein em suas mais diversas facetas de cineasta, teórico, professor e artista (figura 2). A Parte I investiga a crítica cinematográfica brasileira. Nela estão inseridos os capítulos em que se enfatiza a postura dos críticos frente à cinematografia de Eisenstein, em sua grande parte publicada em jornais e periódicos. Entre os textos, apresenta-se de maneira pontual o início da crítica especializada em cinema, reformulada por Paulo Emilio Sales Gomes, um grande incentivador e difusor da linguagem cinematográfica, das teorias do cinema e da montagem de Eisenstein.

Associados a essas críticas, são citados alguns casos da produção artística e cinematográfica brasileira. Nela, seus filmes e suas teorias são estudados e abordados por cineastas brasileiros, que produzem ecos eisensteinianos nas pesquisas

${ }^{4}$ HOUAISS, 2010, p.258. 
acadêmicas que analisam o cinema nacional. Nessa parte, em específico, foi sistematizada a pesquisa de outros colegas a partir de levantamentos bibliográficos, livros, teses e artigos.

A Parte II dedica-se à estreita relação entre o movimento cineclubista e a criação das cinematecas no Brasil. O interessante dessa parte é a conexão entre as exibições dos filmes de Eisenstein e outras linguagens artísticas, ou a associação feita entre estas exibições e os espaços culturais de algumas cidades brasileiras. Nela, a compreensão do contexto social, político e ideológico ajudou a entender o fluxo dos movimentos sociopolíticos que se apropriavam das produções cinematográficas, principalmente russo-soviéticas ou de temática soviética, para discutir e se posicionar a favor ou contra o regime político de sua época: Era Vargas, Ditadura Militar e República Nova. Esta compreensão permeia todas as outras, pois aqui há um entendimento de como as produções artísticas podem ser manipuladas e utilizadas para um discurso ideológico.

Intencionalmente ou não, a filmografia de Eisenstein permite leituras políticas e ideológicas não apenas pelo período em que seus filmes foram produzidos de 1923 a 1944, mas também pela estética adotada, sendo esta última uma característica questionável, segundo muitos estudiosos e críticos de Eisenstein.

Em alguns casos citados na tese, órgãos reguladores deixaram de ter uma função exclusivamente técnica, assumiram um caráter político que incluía a censura e a perseguição do público interessado em Eisenstein, o qual não necessariamente estava vinculado ao Partido Comunista do Brasil (PCdoB) ou a manifestações contrárias ao governo. Por causa dessas proibições, criou-se uma "mística" em torno de seus filmes.

A Parte III da tese é composta pelas relações construídas entre o estudo das teorias de cinema, as traduções de livros e artigos sobre linguagem cinematográfica de Serguei M. Eisenstein e a criação dos cursos superiores de cinema no Brasil, tendo em vista os pontos de contato entre o cineasta russo-soviético e sua produção teórica e fílmica. 


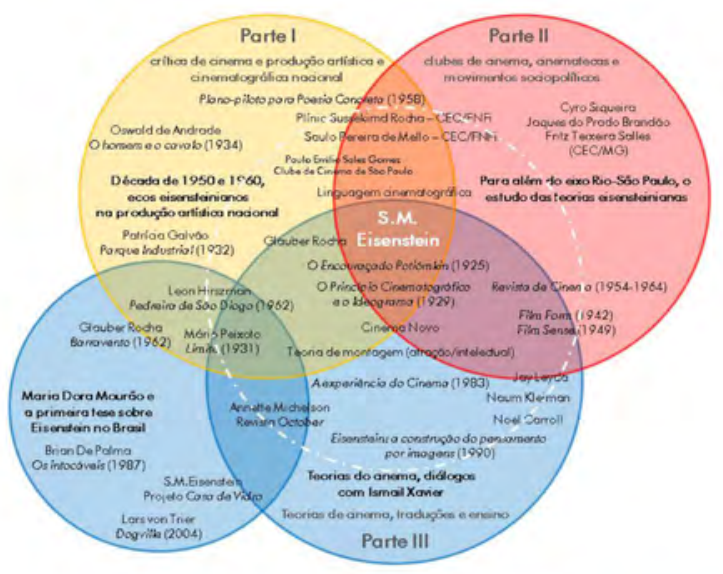

\section{Diagrama de coniunto, modus operandi da teso
Eisenstein no Brosil}

Representados por curvas fechadas simples, tracadas sobre um pertencimento entre os conjuntos e seuss elementos. Do messente modo, os espaços unternos coments a dos ou mais conjunilos

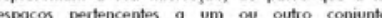
indistintamento sea unioa documentor recollhidos de fonte primaria como possibilidade

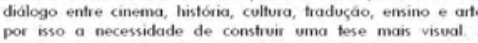

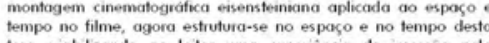
tese viablizando ao leitor uma experiència de imession polo modus operandi da lettura destas paginas, pors em paralelo a

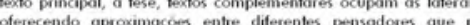
espaço da página encontram-se para suscitar dialogon
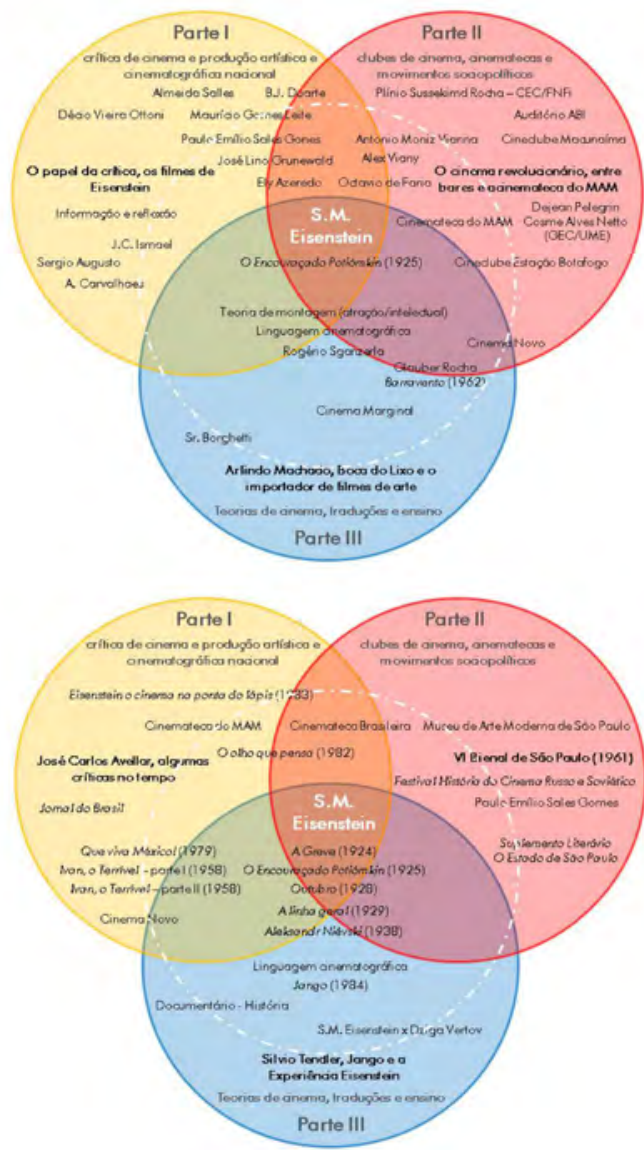

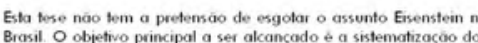
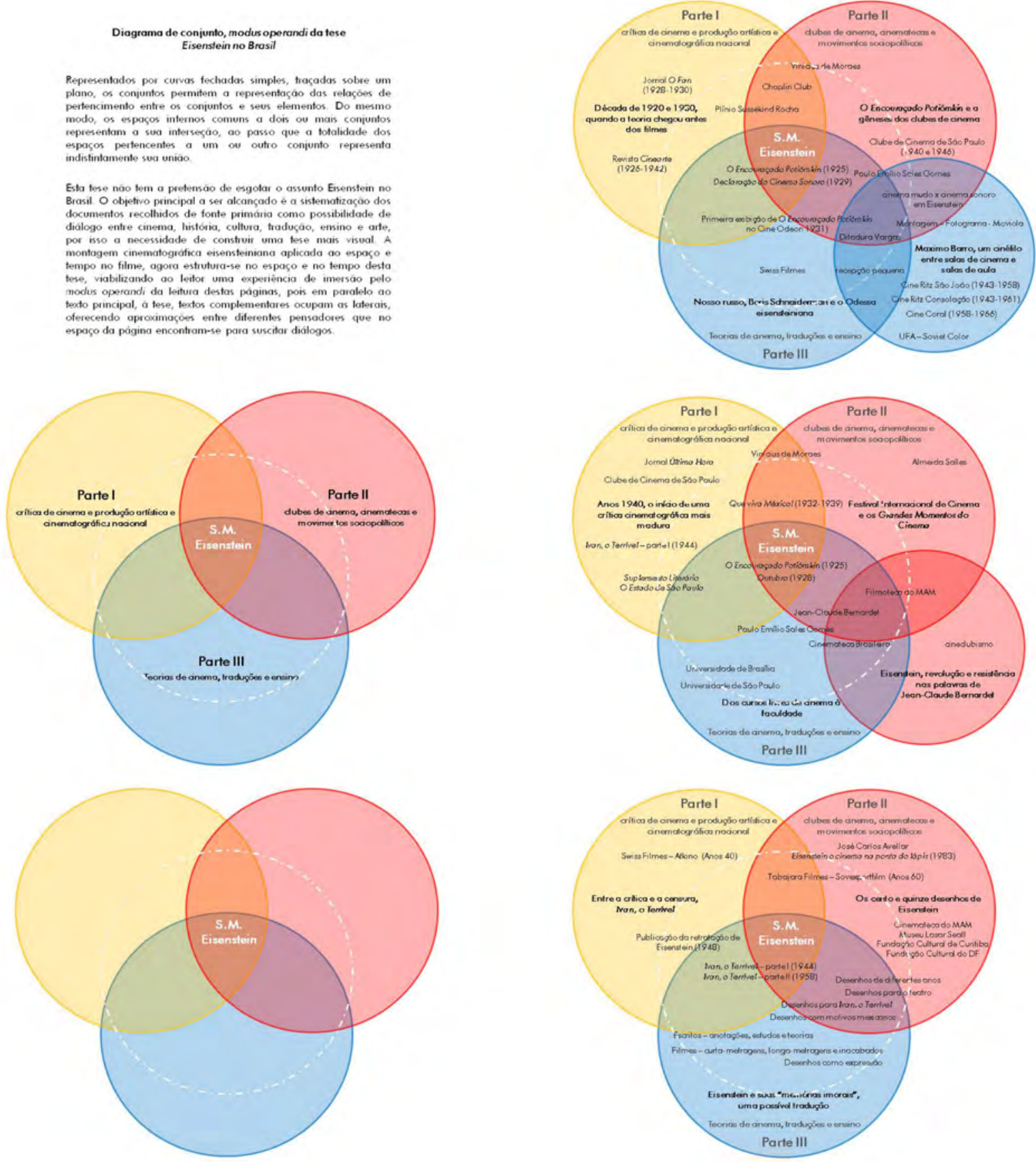
Figura 2: Funcionamento dos conjuntos.

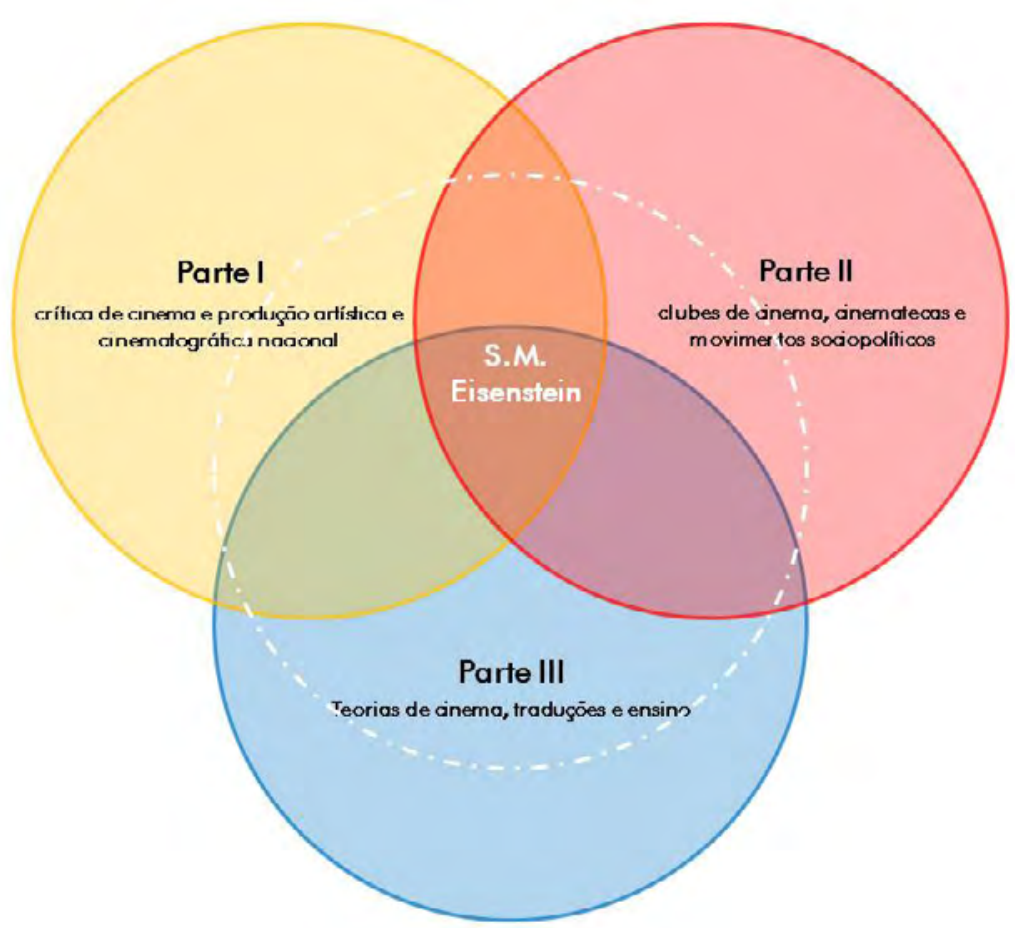

Esta parte é constituída, em sua maior parte, por depoimentos orais recolhidos de maneira informal. Neles, o narrador sente-se à vontade para contar suas histórias, no intuito de contribuir com o objeto de estudo deste trabalho, respondendo à pergunta inicial: "Qual é a influência de Serguei M. Eisenstein em sua vida?".

Para isso, a memória, principal fonte dos depoimentos orais recolhidos, é a chave para o mapeamento de questões culturais, políticas e ideológicas destes intelectuais em suas trajetórias profissionais, pois no processar da memória estão presentes as dimensões do tempo individual (vida privada roteiro biográfico) e do tempo coletivo (social, nacional, internacional).

As narrativas possuem a potencialidade de fazer o ouvinte viajar através da história narrada. Como fontes para construção do conhecimento histórico, elas têm um potencial inesgotável, pois também, como afirma Benjamin, "incorporam as coisas narradas à experiência dos seus ouvintes". ${ }^{5}$ 
Eisenstein no Brasil não tem a pretensão de esgotar o assunto. O objetivo principal a ser alcançado é a sistematização dos documentos recolhidos de fonte primária como possibilidade de diálogo entre cinema, história, cultura, tradução, ensino e arte, por isso a necessidade de construir uma tese mais visual. A montagem cinematográfica eisensteiniana, aplicada ao espaço e tempo no filme, é então estruturada no espaço e no tempo da tese, viabilizando ao leitor uma experiência de imersão pelo modus operandi da leitura destas páginas, pois, em paralelo ao texto principal, à tese, textos complementares ocupam as laterais, oferecendo aproximações entre diferentes pensadores que se encontram no espaço da página para suscitar diálogos.

\section{Um dos capítulos: O Encouraçado Potiómkin e a gêneses dos clubes de cinema}

O Chaplin Club foi fundado em 1928 por Octavio de Faria e Plínio Sussekind Rocha na cidade do Rio de Janeiro. Para pesquisadores da área, é considerado o marco inicial da trajetória do movimento cineclubista no Brasil. O principal objetivo do clube era discutir o cinema como forma de arte, e o jornal $O$ Fan era o veículo de divulgação e de debate das teorias cinematográficas.

Octavio de Faria era adepto da cinematografia do expressionismo alemão e acreditava na força dos planos longos, priorizando a narrativa de seu interior. Plínio Sussekind Rocha defendia o cinema russo e acreditava na força da montagem com uma proposta mais dinâmica e planos mais curtos. De todo modo, ambos acreditavam na expressão pura do cinema através das imagens.

Segundo Constança Hertz, ${ }^{6}$ nos debates do Chaplin Club o cinema russo ocupava um espaço significativo. Pudóvkin e

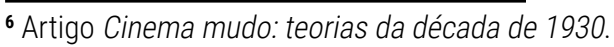


Eisenstein, dentre outros, foram temas de artigos calorosos do grupo. Como naquela época não se tinha acesso aos filmes destes cineastas, as discussões ocorriam a partir de leituras feitas de publicações americanas e europeias, em especial as francesas, que ocupavam um espaço importante para o embasamento teórico.

No penúltimo número de $O$ Fan (1930) foi publicado o manifesto redigido por Eisenstein, Aleksandrov e Pudóvkin sobre o cinema sonoro, de título $O$ cinema sonoro e o manifesto dos três cineastas russos ${ }^{7}$ a partir das versões adquiridas através do New York Times de 7 de outubro de 1928 e da revista francesa Cinéa-Cine de 1930.

Segundo jornais da época, no dia 5 de fevereiro de 1931, na sala vermelha do Cine Odeon, foi exibido o filme $O$ Encouraçado Potiómkin, de Serguei M. Eisenstein. A Sociedade Anônima Empresa Serrador foi a responsável por esse feito que mudaria a realidade dos cineclubistas e admiradores da linguagem cinematográfica.

Em 1940, foi fundado o Clube de Cinema de São Paulo na Faculdade de Filosofia da Universidade de São Paulo. Por meio de projeções, conferências, debates e publicações, tinha como objetivo promover uma melhoria do nível crítico do público de cinema e aproximá-lo de importantes obras-primas da história do cinema, difundindo a teoria cinematográfica, quase desconhecida no Brasil.

Paulo Emílio Sales Gomes foi um dos fundadores do Clube de Cinema, logo após retornar de seu exílio na França, onde teve a oportunidade de conhecer e conviver com Plínio Sussekind Rocha. Foi Plínio quem o introduziu nos "mistérios da arte muda", levando-o aos cineclubes franceses. E foi a partir de uma simples pergunta que Eisenstein entrou em sua vida para nunca mais sair. A pergunta foi a seguinte: "Você, que é comunista, conhece as fitas russas?".

Como o clube não possuía os equipamentos necessários nem os filmes a serem projetados, então "os filmes e o equipamento

7 O Fan, número 8, Rio de Janeiro, 1930. pp. 10-14. 
eram alugados, segundo Paulo Emílio, na Casa Isard, e, segundo Rudá de Andrade, na Mesbla". ${ }^{8}$

O Clube de Cinema despertava a simpatia de vários intelectuais, dentre eles críticos de cinema como Guilherme de Almeida. Mesmo tendo esse reconhecimento no meio cultural, o Departamento de Imprensa e Propaganda (DIP) de Getúlio Vargas o fechou, alegando falta de licença para funcionar.

No entanto, a memória do clube e o debate sobre cinema como arte, iniciado pelo Chaplin Club, continuou por meio das páginas do jornal $A$ Manhã, com artigos e provocações publicadas por Vinicius de Moraes, que possibilitavam assim a continuidade dos debates e exibições cinematográficas e reviviam a velha polêmica entre o cinema mudo e o cinema falado.

A influência do Chaplin Club e a experiência do Clube de Cinema de São Paulo impulsionou Vinicius de Moraes a organizar o Clube de Cinema do Rio de Janeiro em 1942. Com o final do Estado Novo, em 1946, o Clube de Cinema de São Paulo ressurgiria, com uma geração de intelectuais herdeira direta da Universidade de São Paulo e da Escola Livre de Sociologia, organizada por Almeida Salles, Mucio Porphirio e Rubem Biáfora. Para as exibições de filmes, utilizavam o auditório do consulado americano.

No mesmo ano, no Rio de Janeiro, foi fundado o Clube de Cinema da Faculdade Nacional de Filosofia da Universidade do Brasil (FNFi), a partir do incentivo e da participação ativa de Plínio Sussekind. Seu acervo era composto por uma pequena filmoteca, com filmes encontrados em Minas Gerais, e entre eles havia uma cópia de $O$ Encouraçado Potiómkin.

Nos cineclubes se davam as discussões teóricas e políticas. Era um espaço de atração de curiosos e novos participantes do movimento. Em alguns casos, também foram o espaço onde se deram cursos de cinema, já que ainda não existiam no Brasil faculdades e cursos de cinema regulares. ${ }^{9}$

${ }^{8} \mathrm{Jr}$. CORREA, 2010, p.89.

${ }^{9}$ SIMONARD, 2006, p. 70 


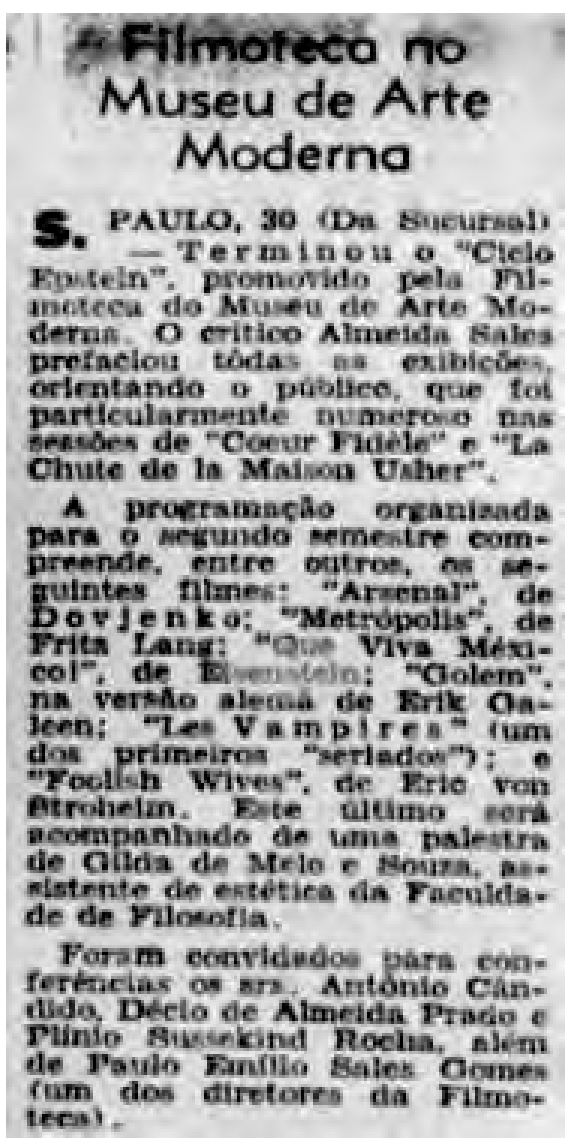

Figura 3: Tribuna da

Imprensa, 30/06/1954.
O Clube de Cinema de São Paulo se tornou modelo referencial para outros cineclubes, ao proporcionar cursos e seminários aos associados, além das tradicionais exibições cinematográficas.

Em março de 1949 foi inaugurado o Museu de Arte Moderna de São Paulo (MAM-SP), a partir da iniciativa de Ciccillo Matarazzo. Em seu início, fora instalado no Museu de Arte de São Paulo (MASP), entidade criada por Assis Chateaubriand em 1947. Era a união de mecenas paulistas a favor do desenvolvimento da cultura nacional.

Desde seu início, o MAM-SP promoveu sessões de cinema organizadas pelo Clube de Cinema de São Paulo. Nele, a pequena filmoteca que Paulo Emílio Sales Gomes organizara para o clube foi incorporada ao Departamento de Cinema do Museu, dando origem à Filmoteca do MAM.

Em 1948, Alex Viany, Antonio Moniz Vianna, Salvyano Cavalcanti de Paiva e Luiz Alípio de Barros fundaram o Círculo de Estudos Cinematográficos (CEC) no Rio de Janeiro. Nesse mesmo ano, o crítico Paulo da Fontoura Gastal inaugurou o Clube de Cinema de Porto Alegre, no Rio Grande do Sul. As cidades de Fortaleza e Santos também receberam agremiações cineclubistas naquele ano.

Em 1954, dentro da programação do Festival Internacional de Cinema do Brasil, Grandes Momentos do Cinema foi um marco para a história da cultura cinematográfica. Com participação de Paulo Emílio Sales Gomes, seu programa visava nitidamente a formação do público, a colocá-lo em contato direto com os filmes de uma linha cronológica já clássica da história do cinema. E entre as películas exibidas, as de Eisenstein eram: o Encouraçado Potiómkin, Que viva México!, Os dez dias que abalaram o mundo/Outubro.

Alguns anos depois, em 1955, a filmoteca começou a apoiar com frequência os cineclubes brasileiros através da distribuição de filmes clássicos, os quais contribuíam para a ampliação de suas programações. Este foi o reflexo de um dos maiores objetivos de Paulo Emílio, a democratização da cultura via ci- 


\section{"Clássicos" na Fa-} culdade de Filosofia

(1) CENTro de Datudo Cinematomíficos da Faculdade de Fllosofia continua com suas sessoes semanais, as sextas-feiras, A nitima apresentaplo fol "Historis de ums Muiher" The Pessionate Friendx), de David Lean, coen Ann Told o Trevor Howard.

Ainda nâo foram fixadus a datas, mas veremos brevemente "O Encourapado Potemkim" "Cavalthelros de Ferro" Alemandre Nevaky). de Elsonstelo, "Mise", de Pudovtin.

Figura 4: Tribuna da Imprensa, 05 e 06/03/1955. neclubes e cinematecas.

Saulo Pereira de Mello e Joaquim Pedro de Andrade, discípulos de Plínio Sussekind Rocha e de sua paixão pela linguagem cinematográfica, juntamente com outros alunos da FNFi, fundaram o Centro de Estudos Cinematográficos (CEC). Com o objetivo de difundir a cultura cinematográfica, entre 1954, ano de sua fundação, e 1955, começaram a procurar pessoas interessadas em incentivar a criação de novos cineclubes dentro de outras unidades universitárias. Numa dessas conversas, Leon Hirszman foi um desses contatos, e com ele surgiu o Clube de Cinema da Escola Nacional de Engenharia.

Em 1956, a Filmoteca do MAM se constituiu como sociedade civil, transformando-se na Fundação Cinemateca Brasileira.

\section{Das considerações finais, uma possível continuidade}

Por que ver, ler e falar de Serguei Mikhailovich Eisenstein hoje? Qual a importância deste cineasta para o público brasileiro? Na tese Eisenstein no Brasil são apresentados pontos de contatos a partir de pessoas e instituições importantes para que seus filmes e suas teorias chegassem até os dias de hoje. Nesse caminhar entre o espaço e o tempo, é possível refletir sobre a influência direta desse cineasta em diálogo com a produção literária, artística, cinematográfica e intelectual brasileira.

$\mathrm{Na}$ tentativa de percorrer e reconhecer o maior número de pontos de contato, constatou-se que estudar Eisenstein hoje é estudar o que há de mais atual tanto em forma quanto em conteúdo, pois sua linguagem e sua teoria são sempre acessadas, logo, renovadas.

Atualmente, seus filmes são exibidos em salas de cinema em ocasiões especiais. No entanto, com o acesso à internet, é possível assistir obras que até então eram restritas ou indis- 
poníveis, e acessar material sobre o cineasta a qualquer hora e em qualquer lugar; são filmes de longa e curta-metragem, fragmentos de gravações de filmagens nas quais o cineasta russo-soviético aparecia, uma infinidade de materiais que só fazem aumentar a sua credibilidade. Porém, essa é uma questão posterior e exterior ao cerne desta pesquisa, que se preocupou em mapear as intersecções entre as obras eisenteinianas e a cultura brasileira.

A questão político-ideológica é outro fator importante de aproximação entre seus filmes e o público, pois ainda vivenciamos ditaduras e assistimos às mesmas atrocidades neles representadas, ou seja, há uma identificação direta quanto ao tema abordado, o que não diminui a qualidade plástica e conceitual da obra, afinal, para o cineasta, a linguagem cinematográfica não está subordinada à representação da realidade, mas faz parte dela.

Sua obra transcende o fato de ter sido realizada em plena revolução soviética, ocorrida na Rússia a partir de 1917, pois Eisenstein tinha uma clara consciência a respeito da potencialidade da linguagem cinematográfica como instrumento político, social, mas também como arte.

Um filme só se torna cinema quando é projetado para seu espectador, quando o processo de formação das imagens ocorre de maneira sensível na inteligência daquele que o recebe, e com o qual interage por meio da montagem. Por este objetivo, é essencial pensar sobre a recepção de sua obra no Brasil.

Da ação às ideias, uma necessidade ideológica. Em sua primeira fase, o cinema mudo, Eisenstein enfatiza a ideia de radicalizar na fragmentação do tempo e do espaço, em oposição à narrativa clássica. Em especial, $O$ Encouraçado Potiómkin é o seu filme mais citado, estudado e aclamado no Brasil. Essa afirmação é possível devido a alguns fatores: foi o primeiro filme a ser exibido em meados de 1930, o mais censurado, permaneceu proibido durante quinze anos pela Ditadura Militar, e, ao mesmo tempo, obteve maior repercussão internacional por ter sido eleito em 1926, pela Academia Americana de Ar- 
tes, o melhor filme do mundo. Em resumo, por estes três fatores determinantes, o filme foi citado por um maior número de periódicos, conforme comprovado pelas fontes primárias acessadas.

David Bordwell no livro El cine de Eisenstein (1999) faz um rápido traçado das marcas eisensteinianas encontradas na teoria do cinema e na filmografia de alguns cineastas. Segundo ele, o cinema de Eisenstein exemplifica a nova forma de leitura exigida pela literatura e arte contemporânea. Jacque Aumont no livro Pour un cinéma comparé: influences et répétitions (1996), faz uma pesquisa similar, percebendo em Glauber Rocha a mesma organização de sistemas de contradições (conflitos), elemento básico da montagem de atrações.

O Brasil foi um dos países que recepcionou as suas obras, outros tantos também o fizeram e ainda o fazem, o que se pode perceber pela infinidade de eventos acadêmicos e artísticos que discutem e (re)apresentam o eterno contemporâneo Serguei M. Eisenstein.

\section{Referências bibliográficas}

BENJAMIN, Walter. Obras Escolhidas: Magia e técnica, arte e política. (Trad. de Sérgio P. Rouanet.) São Paulo: Brasiliense, 1996.

DEPARTAMENTO DE LETRAS ORIENTAIS. Tabela de transliteração do russo para o português. São Paulo: Editora Ateliê: 2004. 1p.

DERDYK, Edith. Linha do Horizonte: por uma poética do ato criador. São Paulo: Intermeios, 2012.

EISENSTEIN, Serguei. Memórias imorais: uma autobiografia. (Trad. de Carlos E. M. de Moura.) São Paulo: Companhia das Letras, 1987.

HERTZ, Constança. "Cinema mudo: teorias da década de 1930". Disponível em: <www.ciencialit.letras.ufrj.br/garrafa4/8.doc >. Acessado: 12 junho 2018. 
HOUAISS, Antônio. Minidicionário Houaiss da língua portuguesa; elaboração no Instituto Antônio Houaiss de Lexicografia e Banco de Dados da Língua Portuguesa, 4 ed. ver. e aumentada. Rio de Janeiro: Objetiva, 2010.

IVÁNOV, V. V. Dos diários de Serguei Eisenstein e outros ensaios. (Trad. de Aurora F. Bernardini e Noé Silva.) SãoPaulo: EDUSP, 2009.

Jr. CORREA, Fausto Douglas. A Cinemateca Brasileira: das luzes aos anos de chumbo. São Paulo: Editora UNESP, 2010.

NIZHNY, Vladimir. Lecciones de cine de Eisenstein. (Trad. de Leoncio S. Guytó e Román Gubern.) Barcelona: Editorial Seix Barral, 1964.

XAVIER, Ismail. Sétima Arte: um culto moderno. São Paulo: Perspectiva, 1978. 